\title{
The Turbulence of Vaporized Magma in the Chamber at Eruption is akin to its Behavior as an Ideal Gas
}

\author{
Dr.(Prof.) V.C.A. NAIR* \\ Distinguished Alumnus, Chancellor-designated Resource Person in the area of Physics, \\ Research Guide for Physics at Shri J J T University, Jhunjhunu, Rajasthan-333001, India. \\ Research Scholar registered for the Degree of Doctor of Science (D.Sc) in \\ Madurai Kamaraj University, Madurai-625021, Tamil Nadu, India \\ *nairvca39@gmail.com
}

\begin{abstract}
The Author begins with a meaning of the Title. A diagrammatic illustration from the point of view of location of Magma Chamber inside the Earth is given. Idea of Magma Convection inside the Magma Chamber leading to Magma Fragmentation and Magma Vaporization which ultimately leads to Magma Turbulence. In the Paper the author has established the fact that at Eruption, the gaseous or more correctly the vaporous Magma behaves as an Ideal Gas obeying the Gas Laws more particularly the Gay-Lussac's Law. The lowest and highest temperatures of the vaporous magma have been found from the Review of Literature and the Gay-Lussac's Law has been graphically plotted. From the slope of the graph, the value of the Gas Constant ' $R$ ' is found to be fairly in good agreement with its standard value.
\end{abstract}

Readers are requested to particularly read the Conclusion.

Keywords: Charle's Law, Eruption, Gay-Lussac's Law, Gas Constant, Ideal Gas, Magma Chamber, Magma Fragmentation, Magma Turbulence, Magma vaporization, Perfect Gas

\section{INTRODUCTION}

1. The Title: Readers should not get surprised by using the word, 'Gas' in the title of the Paper. In addition to Gas, the laws and rules of Thermodynamics can be applied even to fluids, that is, both liquids and gases. Molten magma at eruption is so vaporized that it can be legitimately treated as a Gas and Gas Laws can be applied

\section{REVIEW OF LITERATURE}

\section{THE MAGMA CHAMBER}

2. Location inside the Earth: Fig. 1 gives the structural details from the point of view of location of Magma Chamber inside the Earth. The dimensions given vary from author to author. Physics, so is Geophysics, requires lot of imagination. You may look at an eruption of a volcano which has taught many things inside the Earth even though one cannot look at a magma chamber like site seeing. The values given are approximate. Coming to the size of a magma chamber, I have mentioned in one of my other Research Paper that the size of the magma chamber of a volcano of VEI 8 is almost equal to the size of the entire San Francisco Bay from Sacramento to San Jose in the California State of US. To compare with any place in India near Mumbai, the size can be taken as the area covering either Palghar or Thane districts of Maharashtra in India.

2.1 Normal and steady Convection of Magma in the Chamber: At equilibrium states, the magma in the chamber is a well set thermodynamic system maintaining constancy of temperature due to normal and steady convection. Steady convection exists as the magma at lower part being near the upper part of the mantle is at a high temperature $\mathrm{T}_{1}$ (Fig.2) and hence of low density. The low density magma rises above 


\section{International Advanced Research Journal in Science, Engineering and Technology}

Vol. 6, Issue 8, August 2019

meet with the layers of crust and get cooled. The cooled magma with a slightly low temperature $T_{2}$ becomes lighter and comes down and again becomes hot and moves up. $\left(\mathrm{T}_{1}>\mathrm{T}_{2}\right)$. This is a normal and steady convection and is stable existing in all magma containers including the mantle which, in fact, is considered as an ocean of magma. $\mathrm{L}$ is the width or height of the magma Chamber that is the distance between the hot and cold face or the distance between the outlet to the volcano and the inlet from the mantle.

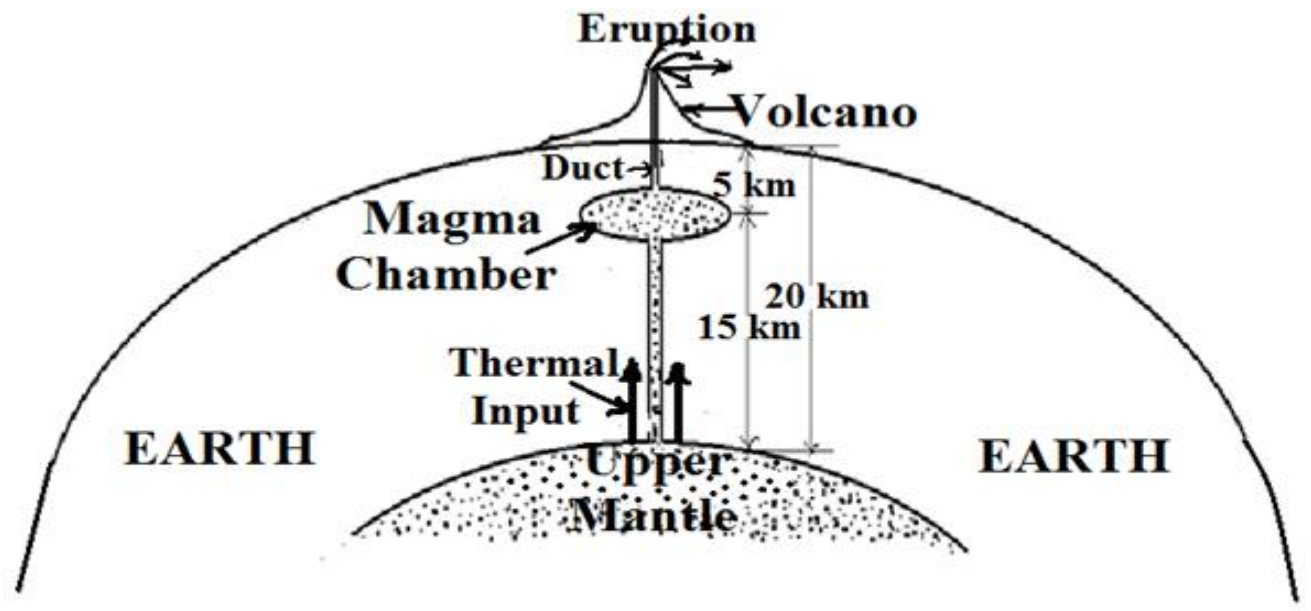

M A N T L E

Fig.1 Location of Magma Chamber inside the Earth (A Free-hand Diagram by Author)

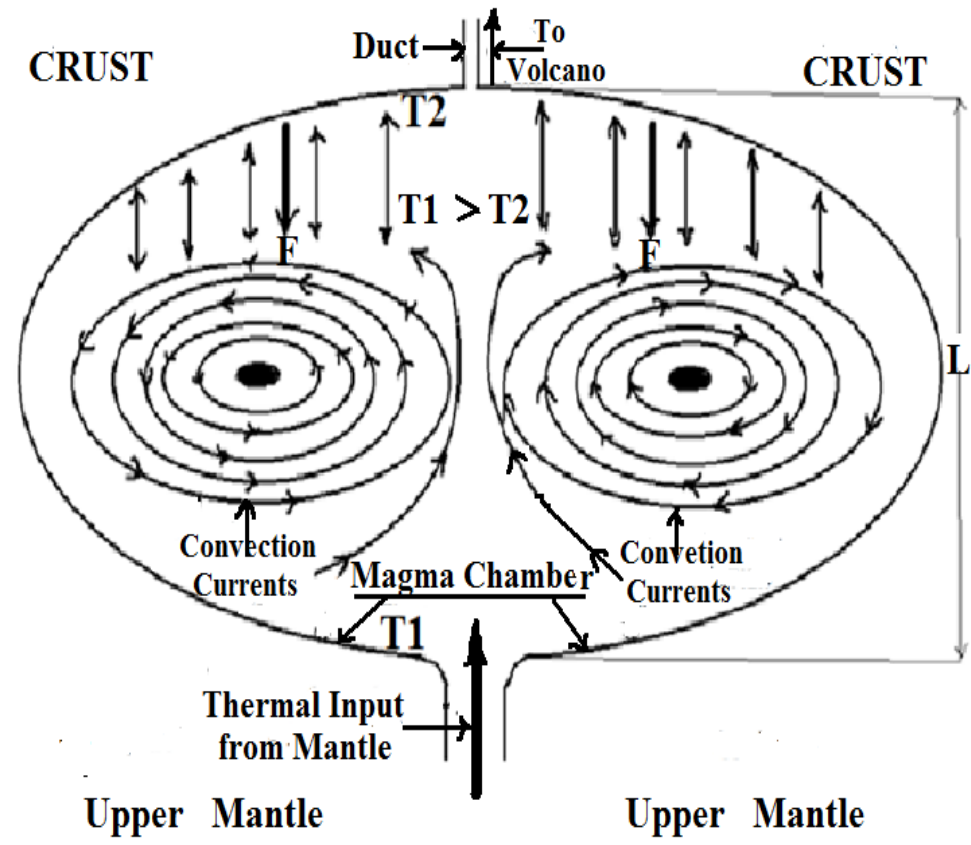

Fig.2 Illustration of Convection of Magma in the Chamber (A Free-hand Diagram by Author)

\section{THE TURBULENCE OF MAGMA IN THE CHAMBER}

3. The Cause and Effect: The development of Physics has taken place by the study of the Formalism of 'Cause' and 'Effect'. If the eruption of volcano is the 'Effect', the 'Cause' is the magma in the chamber. Some information is given here by a Journalist. All journalists are not scientific minded, but this Thea Jacobs [5] appears to be having fairly a good knowledge of volcanoes. To the question, "What makes a volcano erupt?" He gives the following points: 


\section{International Advanced Research Journal in Science, Engineering and Technology}

Vol. 6, Issue 8, August 2019

*There are several different causes for a volcano to erupt which all fundamentally come down to a pressure change within the volcano which forces the magma to overflow the chamber it is held in.

*The most common type of eruption is caused by the movement of tectonic plates. when one is pushed under the other the magma, sediment and seawater is forced into the chamber which eventually overflows and the volcano erupts spewing lava into the sky. This kind of eruption produces sticky, ' thick lava at temperatures from 800 to $1,000 \mathrm{C}$.

1

* The second type of eruption caused by tectonic plates is when the plates move away from each other allowing magma to rise and fill the the gap, which can cause a gentle explosion of thin lava of temperatures between 800 to $1,200 \mathrm{C}$. Decreasing temperatures can cause old magma to crystallize and sink to the bottom of the chamber and this movement can force fresh liquid magma up and out similar to dropping a brick in a bucket of water.

* Finally a decrease in external pressure can trigger an eruption as it may minimize the volcano's ability to hold back by increasing the pressures inside the magma chamber.

This kind of eruption can be caused by natural events such as typhoons, which decrease rock density, and glacial melting on the top of the volcano which alters the molten rock composition.

In spite of many causes given by Mr. Thea Jacobs, the author of this Paper is not satisfied rather not fully satisfied. Keeping in view of the title of the Research Paper, some of the points given by Thea Jacobs may be partly correct, but none of them can be brought to link with magma as a Gas.

3.1 The Turbulence: In the state of steady convection which is normal and natural, the magma is more a liquid than a Gas. Some perturbation or disturbance has to take place in the chamber so as to creat an instability of convection leading to both increase of temperature, $\mathrm{T}$ and pressure, $\mathrm{P}$. The following are the agencies which will facilitate to do this job:

- Entry of some additional magma from the Upper Mantle which may not create an increase in temperature, but certainly will increase the heat-content of magma and hence its Entropy. The author has dealt with this case separately in another research paper.

- Some crustal changes bordering the walls of the chamber may also create a perturbation.

- Entry of water into the chamber may create a perturbation and there are cases where it has created explosive eruptions.

- Any equilibrium state of magma in the Mantle can also affect the equilibrium state of magma in the Chamber.

- Some natural, but unknown perturbation for example, the rotation of the Earth can also create a perturbation.

The moment a perturbation is created which when becomes uncontrollable, there will be magma turbulence leading to fragmentation and vaporization of magma in the chamber as a result of which the temperature and pressure increases tremendously making the magma behave as a Gas. This is the main stage required for an eruption.

For a confirmatory evidence, readers may refer Helge M. Gonnermann's [2] Research Paper titled "Magma Fragmentation" the contents of which is given below in Italics:

"Magma Fragmentation is the breaup of a continuous volume of molten rock into discrete pieces, called pyroclasts. As magma contains bubbles of compressible magmatic volatiles, decompression of low viscosity magma leads to rapid expansion. The magma gets torn into fragments as they are stretched into hydrodynamically unstable sheets and filaments. If the magma is highly viscous, the resistance to bubble growth will instead lead to excess gas pressure and the magma will deform visco-elastically by fracturing like a glassy solid, resulting in the formation of A VIOLENTLY EXPANDING GAS-PYROCLAST MIXTURE. If magma comes into contact with external water, the resulting thermal energy will vaporize water and 


\section{International Advanced Research Journal in Science, Engineering and Technology}

Vol. 6, Issue 8, August 2019

quench magma at the melt-water interface, thus creating dynamic stresses that cause Fragmentation and the release of kinetic energy."

\section{PERFECT GAS AND IDEAL GAS}

4. Vaporized Magma: With the Review of Literature so far given and specifically the section 3.1 above, we are cock sure that at certain conditions, magma can behave as a Gas. That is, we can legitimately and rightly say that magma can behave as a Gas. Vaporized magma is not a Perfect Gas, but an Ideal Gas. What then is the difference between a 'Perfect Gas' and an 'Ideal Gas'? Nathaniel H. Frank [4] has distinctly made clear the difference between the two. Both the Perfect Gas and Ideal Gas obey the equation of state,

$$
\mathrm{PV}=\mathrm{nRT} \ldots \ldots \ldots \ldots \ldots \text { (1) }
$$

Where $\mathrm{P}$ is the pressure, $\mathrm{V}$ the volume, $\mathrm{n}$ the number of moles present in the gas, $\mathrm{R}$ the Universal Gas Constant and $\mathrm{T}$ the Absolute Temperature. The author considers a peculiar type of expansion of a gas by a thought experiment such as a 'Free Expansion' in which a certain quantity of gas is suddenly allowed to expand in vacuum. It is found that in such a Free Expansion, for a gas to be Perfect, there should be no change in temperature. The author says that, "We demand of a Perfect Gas that there should be no temperature change in a free expansion". That is to say that if there is a change in temperature, the gas will be an ideal gas. The author [4] further continues:

"This means that the internal energy $E$ of an ideal gas does not depend on the volume, $V$ occupied by the gas but only on the temperature, $T$." The author writes this condition analytically in the form:

$$
\mathrm{E}=\mathrm{E}(\mathrm{T}) ; \quad \mathrm{E} \neq \mathrm{E}(\mathrm{V})
$$

This condition (2) together with the equation of state (1), $P V=n R T$ completely and uniquely defines an Ideal Gas"

Now, coming to our situation of Magma in the chamber, the volume of the chamber is fixed and not variable. The energy of magma is a function of both the Temperature, $T$ and the pressure, P. We can, now, emphatically call the vaporized magma in the chamber as an Ideal Gas and apply a suitable Gas Law. The suitable Gas Law is the Gay-Lussac's Law or the same law also known as the Second Charle's law.

\section{THE GAS LAWS}

5 Gay-Lussac' Law or Second Charles Law: Jacques Charles the French inventor, scientist and mathematician (Fig.3)

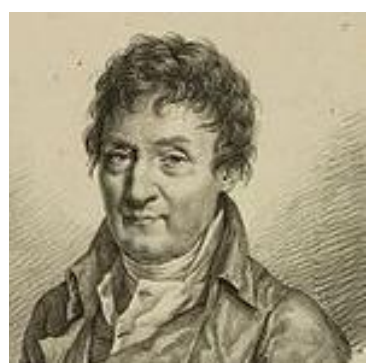

Fig.3 Jacques Charles $(1746-1823)$

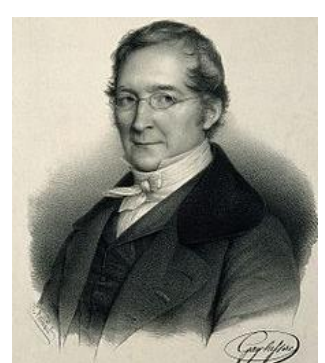

Fig.4 Joseph Louis Gay-Lussac (1778 - 1850)

found a relation between the volume and temperature of a certain quantity of gas and stated that by keeping the pressure constant, the Volume $\mathrm{V}$ of a certain quantity of gas is directly proportional to its absolute temperature, $\mathrm{T}$. That is, $\mathrm{V} \propto \mathrm{T}$ or $\frac{\mathrm{V}}{\mathrm{T}}$ is constant. This law of Charle's remained an un-published work and later a French Physicist and Chemist Joseph Louis Gay-Lussac (Fig. 4) not only published the Law of Charles and stated, in addition to, that the pressure, $\mathrm{P}$ exerted by a certain quantity of gas is also directly proportional to the absolute temperature, $\mathrm{T}$. That is, $\mathrm{P} \propto \mathrm{T}$ or $\frac{\mathrm{P}}{\mathrm{T}}$ is constant and this statement is known as the Gay-Lussac's Law or the second Charle's law. 
5.1 The Gay-Lussac's law applied to Vaporous Magma in the Chamber: The relation, $\frac{P}{T}$ is constant is also applicable to the behavior of magma in the chamber. Let us clarify the constant in the relation. The constant of proportionality is equal to the number of moles, $\mathrm{n}$ present in the gas and another constant, $\mathrm{R}$ called the Universal Gas Constant. That is,

$$
\mathrm{P}=\mathrm{nR} \mathrm{T} \text {. }
$$

Equation (1) is called the Universal Gas Equation, For 1 mole or 1 kilo mole of a gas,

$$
\begin{aligned}
& \mathrm{P}=\mathrm{R} \mathrm{T} \\
& \frac{\mathrm{P}}{\mathrm{T}}=\mathrm{R}
\end{aligned}
$$

The standard value of $\mathrm{R}$ is $8314 \frac{\mathrm{J}}{\mathrm{kg} \mathrm{mole} \mathrm{K}}$. Mole is usually not written and hence the unit is $\frac{\mathrm{J}}{\mathrm{kg} \mathrm{K}}$. In addition to gases, the law can be applied as mentioned earlier to fluids such as molten magma in the chamber. The molten magma is akin to weakly ionized plasma for which general laws of Thermodynamics and Fluid Mechanics can be applied.

5.2 Graphical Study: A graphical representation of the Gay-Lussac's law is shown in Fig.5 which is an indicator diagram in the language of Thermodynamics. The plotting required at least a pair of fixed points Gabriele Lanzafame, et.al [1] has given a pair of fixed points for the Pressure, $\mathrm{P}$

$$
2 \mathrm{M} \mathrm{Pa}\left(2000 \frac{\mathrm{kg}}{\mathrm{m}^{3}} \text { at } 100 \mathrm{~m} \text { and } 9 \mathrm{MPa} 3000 \frac{\mathrm{kg}}{\mathrm{m}^{3}} \text { at } 300 \mathrm{~m}\right.
$$

These values tally with values shown by other researchers. We now require the corresponding values for the Temperature.

Laura Schaefer and Bruce Fegley Jr.[3] has shown "The temperature-dependent pressure and composition of vapor in equilibrium with lava is calculated from 1700 to $2400 \mathrm{~K}$ for 109 different silicate lavas in the $\mathrm{O}-\mathrm{Na}-\mathrm{K}-\mathrm{Fe}-\mathrm{Si}-\mathrm{Mg}-\mathrm{Ca}-\mathrm{Al}-\mathrm{Ti}$ system." But, the authors have not given any lower values

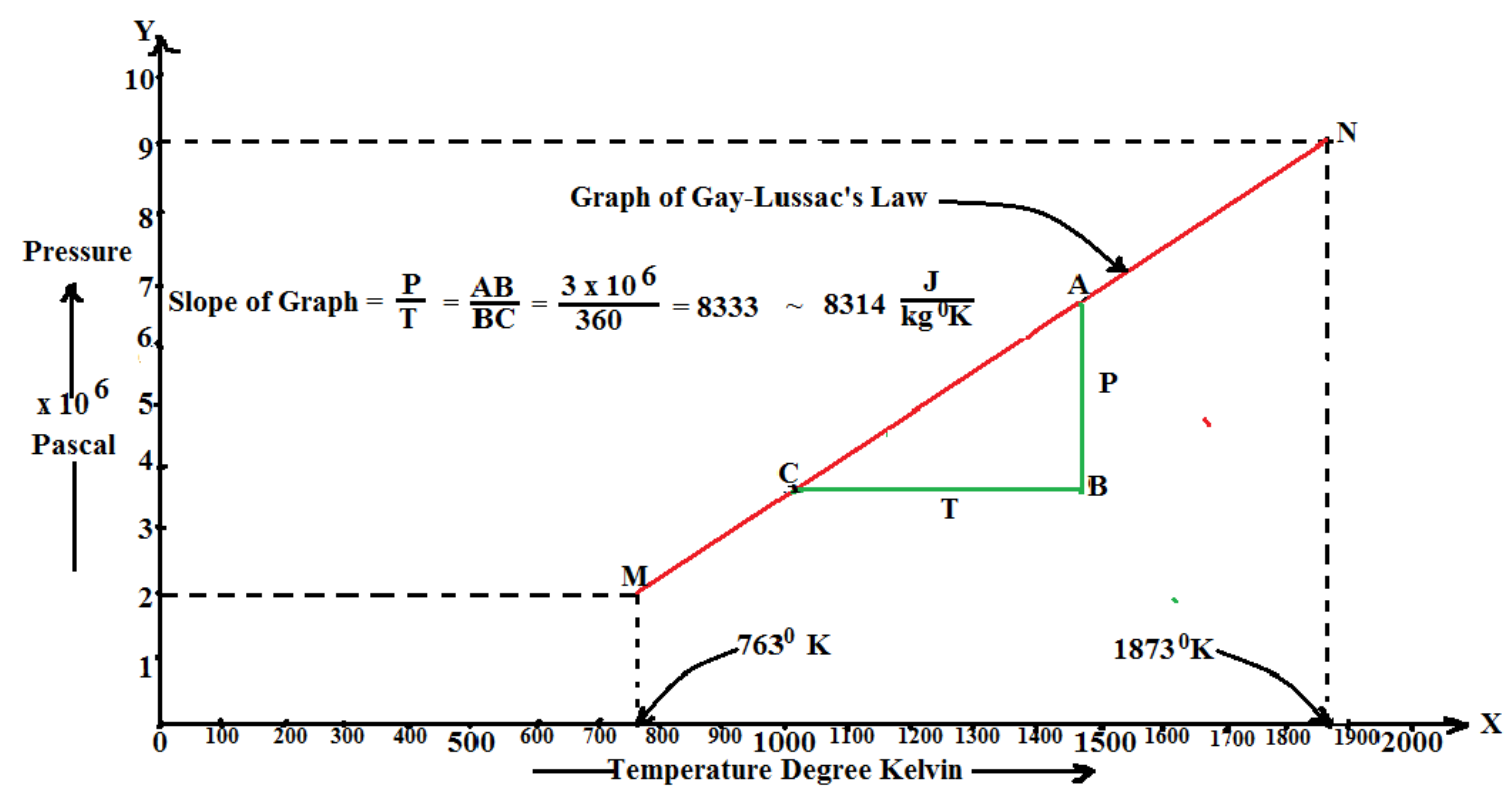

Fig.5 Illustration of Gay-Lussac's Law (Graph, a free-hand diagram by author)

Wikipedia [6] is many times a last resort and a solace for many researchers like me. It is mentioned that "Temperatures of most magmas are in the range $700{ }^{\circ} \mathrm{C}$ to $1300{ }^{\circ} \mathrm{C}$ ( or $1300{ }^{\circ} \mathrm{F}$ to $2400{ }^{\circ} \mathrm{F}$ ), but very rare carbonatite magmas may be as cool as $490^{\circ} \mathrm{C},,^{[13]}$ and komatiite magmas may have been as hot as $1600^{\circ} \mathrm{C}^{\prime \prime}$

We have thus obtained a pair of fixed points for the Temperature keeping in mind that the temperature should be in the Absolute Scale. The final graph obtained is shown in Fig.5 with the Gay-Lussac's law denoted by the straight line $\mathrm{MN}$ with co-ordinates as follows: 


$$
\begin{aligned}
& \mathrm{M}\left(763^{0} \mathrm{~K}, 2 \times 10^{6} \mathrm{~Pa}\right) \\
& \mathrm{N}\left(1873^{0} \mathrm{~K}, 9 \times 10^{6} \mathrm{~Pa}\right)
\end{aligned}
$$

In Thermal Physics, the graph is a straight line $\mathrm{Y}=\mathrm{m} \mathrm{X}+\mathrm{c}$ with the slope giving the ratio $\frac{\mathrm{P}}{\mathrm{T}}$ and the intercept leading to Absolute Zero, $0^{0} \mathrm{~K}\left(-273.16^{\circ} \mathrm{C}\right)$ for which the scales of the graph has to be modified. We are satisfied by the straight-line nature of the graph and we now proceed to find the slope of the graph.

$$
\text { Slope }=\frac{\mathrm{P}}{\mathrm{T}}=\frac{\mathrm{AB}}{\mathrm{BC}}=\frac{3 \times 10^{6}}{360}=8333 \approx 8314 \frac{\mathrm{J}}{\mathrm{kg}^{0} \mathrm{~K}}
$$

This is in agreement with the standard value of the Universal Gas Constant confirming thereby that the Magma in the Chamber is an ideal Thermodynamic System. Slight variations can be expected as the graph is only approximate and strictly not as per scale.

5.3 Tally for the Units and Dimensions: We have the Gas Equation (1), $P$ V $=n R T$

Unit of $\mathrm{P} \rightarrow \frac{\mathrm{N}}{\mathrm{m}^{2}} ; \mathrm{V}$ is unit volume $=1 \mathrm{~m}^{3} ; \mathrm{n}=1 \mathrm{~kg}$ mole; $\mathrm{T} \rightarrow{ }^{0} \mathrm{~K}$

But, $1 \mathrm{Nm}=1$ Joule

$$
\therefore \quad \frac{\mathrm{PV}}{\mathrm{nT}} \rightarrow \frac{\frac{\mathrm{N}}{\mathrm{m}^{2}} \mathrm{~m}^{3}}{\mathrm{~kg} \mathrm{~mole}^{0} \mathrm{~K}} \rightarrow \frac{\mathrm{N} \mathrm{m}}{\mathrm{kg}^{0} \mathrm{~K}}
$$

$$
\therefore \quad \mathrm{R} \rightarrow \frac{\mathrm{J}}{\mathrm{kg}{ }^{0} \mathrm{~K}}
$$

Thus, the formula is dimensionally correct.

Various temperatures of magma in the Chamber and their corresponding pressures and vice versa can be obtained from the graph and the same is shown below. It is something like taking readings from a graph rather than plotting a graph from the readings.

Table No.1

\begin{tabular}{|c|c|c|c|}
\hline No & Pressure P, M Pa & Temperature, $\mathbf{T}^{\mathbf{0}} \mathbf{K}$ & Temperature, $\mathbf{T}^{\circ} \mathbf{C}$ \\
\hline 1 & 2 & 763 & 490 \\
\hline 2 & 3 & 930 & 657 \\
\hline 3 & 4 & 1080 & 807 \\
\hline 4 & 5 & 1220 & 947 \\
\hline 5 & 6 & 1400 & 1127 \\
\hline 6 & 7 & 1530 & 1257 \\
\hline 7 & 8 & 1680 & 1407 \\
\hline 8 & 9 & 1873 & 1600 \\
\hline
\end{tabular}

\section{THE ERUPTION}

An eruption involves three different processes: fragmentation of the magma; blasting of the fragmented mass through the vent to the surface, and the ascent of the eruption column. An explosive eruption may take place if the pressure within the magma exceeds the strength of the surrounding rock. These explosive eruptions are driven by the thermal energy stored in the magma. The thermal energy is transferred into kinetic energy of the eruption column through the expansion of gases into growing vesicles (air bubbles). 


\section{International Advanced Research Journal in Science, Engineering and Technology}

Vol. 6, Issue 8, August 2019

\section{CONCLUSION}

6. General: We have shown in the Paper that the Magma in the Chamber is an ideal thermodynamic system in conformance with the title of the Paper. Going through the entire Review of Literature from the Google Search and the Directory of Open Axis Journals (DOAJ), the author has hardly noticed any article directly pertaining to the subject matter of this Paper.

Any comments or suggestions from readers will be highly appreciated. The readers can contact the author in his E-Mail: nairvca39@gmail.com.

6.1 Personal: It is interesting and really proud of the author to mention here that he celebrated his $75^{\text {th }}$ Birthday on $15^{\text {th }}$ August 2014 at the Foot-Hills of two Volcanoes, Mount Shastha and Mount Lassen Peak in Northern California, USA. Photo can be sent on request.

Note: Research Methodology has been exclusively followed throughout the Paper. Except the photographs of two scientists, all diagrams are drawn free-hand by Author.

\section{REFERENCES}

[1]. Gabriele Lanzafame, et.al: Solidification and Turbulence (Non-linear) during Magma Ascent: Journal of Petrology, Vol. 58, Issue 8: August 2017, pages 1511-1533, (Specific p. 1525) Published on 3 Oct. 2017.

[2]. Helge M. Gummermann, Department of Earth Science, Rice University, Houston, Texas, US: "Magma Fragmentation", Annual Review of Earth \& Planetary Sciences: Vol.43:431-458 (Volume Publication date May 2015

[3]. Laura Schaefer and Bruce Fegley Jr.: "A thermodynamic model of high temperature lava vaporization on Io" Planetary Chemistry Laboratory, Department of Earth and Planetary Sciences, Washington University, One Brookings Dr., Campus Box 1169, St. Louis, MO 63130, USA Received 1 April 2003; revised 23 July 2003.

[4]. Nathaniel H Frank: "Introduction to Mechanics and Heat":Ch. XX. Thermodynamics and Kinetic Theory of an Ideal Gas, Sec. 130, Thermodynamic definition of an Ideal Gas, p.298: Mac Graw Hill Book Company Inc. New York \& London, 1934.

[5]. Thea Jacobs: Journalist, The Sun, 10 May 2018

[6]. Wikipedia: Edited on 28 June 2019

\section{BIOGRAPHY}

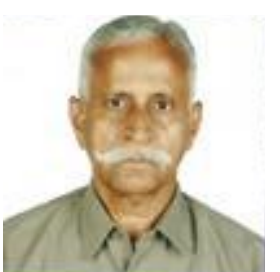

*Dr.(Prof.) V.C.A. Nair (b.15th Aug. 1939) is an Educational Physicist, Counselor, Research Guide and Consultant. He did his Masters in Physics from Mumbai University, India and Ph.D. from Shri. JJT University, Rajasthan also in India He is a Research Guide and distinguished alumni of JJT University. He is also a Chancellor designated Resource Person in the area of Physics in the University. He has to his credit over 4 decades of teaching Applied Physics in eminent Polytechnics in Mumbai and having taught nearly 16,000 students since 1965. He has published a number of research papers in Physics and Geophysics in International and UGC recognized Journals some of which can be seen in the net 'Google Search' when the name of the author or his e-mail is clicked in that style. He is a Life Member of Indian Society for Technical Education which is an all India body. He had been to USA a number of times and visited eminent Universities such as Stanford, Harvard, MIT, 3 Universities of California at Berkeley, Los Angeles and also at Davis ,University of Princeton at New Jersey, Roosevelt University at Chicago, University of Chicago and University of San Francisco. At present Dr. Nair is a Research Guide for Physics at Shri JJT University, Rajasthan-333001, India .He is a registered candidate for the Degree of Doctor of Science (D.Sc) of Madurai Kamaraj University, Tamil Nadu, India.

$\mathrm{He}$ is a member of the Editorial Board of this Journal. His Ph.D. Thesis is in Geophysics and he is working on topics such as Tides, Clouds, Global Warming and Climate Change. - Editor.

*nairvca39@gmail.com 